\title{
A study of drug utilization in indoor patients of high-risk pregnancy in a tertiary care hospital
}

\author{
Smita Laxman Gaidhankar, Shraddha Milind Pore, Milin Nanasaheb Deokate*, \\ Sunita Jaiprakash Ramanand, Arundhati Tukaram Salunke
}

Department of Pharmacology, Government Medical College, Miraj, Maharashtra, India

Received: 21 April 2016

Accepted: 03 June 2016

\section{*Correspondence to:}

Dr. Milin Nanasaheb Deokate, Email: milindeokate@ gmail.com

Copyright: () the author(s), publisher and licensee Medip Academy. This is an openaccess article distributed under the terms of the Creative Commons Attribution NonCommercial License, which permits unrestricted noncommercial use, distribution, and reproduction in any medium, provided the original work is properly cited.

\begin{abstract}
Background: High-risk pregnancy is an important determinant of drug use during pregnancy. The aim of study was to evaluate drug use pattern according to WHO core-drug prescribing indicators and US-FDA pregnancy category in indoor patients of high-risk pregnancy.

Methods: It was a prospective, observational study. All high-risk pregnant women admitted to tertiary care hospital and willing to give consent were included. The data was collected from 290 patients over 12 months. The data was analysed to evaluate drug utilization according to WHO core drug use indicators and in relation to US-FDA pregnancy risk category.

Results: The study found that $74.82 \%$ of women were between $20-30$ years of age and were admitted during third trimester of pregnancy. The most commonly prescribed drug class was vitamins and minerals prescribed in $82.75 \%$ patients. Average number of drugs per encounter was 6.4. Percentage of drugs prescribed by generic name and from essential drug list was $73.07 \%$ and $77.07 \%$ respectively. Percentage of encounters with an antibiotic and an injection prescribed was $29.31 \%$ and $65.17 \%$ respectively. The prescription of drugs belonging to US-FDA pregnancy drug categories A, B and C were 92.06\%, $86.55 \%$ and $4.82 \%$ respectively.

Conclusions: Overall, the principles of rational prescribing were followed according to the various drug use indicators mentioned by the WHO and US FDA pregnancy risk category. Further studies are required to find out specific drug or drug therapy related problems and plan targeted interventions to improve drug use.
\end{abstract}

Keywords: WHO core drug use indicators, US-FDA pregnancy drug category, Antihypertensives

\section{INTRODUCTION}

The significance of drug utilization research in improving health care is now well accepted. While clinical trials provide evidence of efficacy, drug utilization research is necessary for knowing extent of drug use, identifying variability in drug use among different regions or within the region, identifying problems concerning inappropriate use of drugs, planning targeted interventions to improve drug use and to measure impact of these interventions. ${ }^{1}$

Evaluation of drug-utilization in patients with high-risk pregnancy is important for several reasons. Firstly, pregnancy itself poses a difficult challenge to use of drugs mainly because of risk of harmful effects to unborn fetus and also due to physiological changes induced in mother during pregnancy. Secondly, literature search shows that drug-utilization during pregnancy is quite common and varies from region to region and within the region over time. ${ }^{2-4}$ Moreover, introduction of newer and better therapeutic agents in practice leads to increased exposure of pregnant women to these drugs., 5 Consequently, drug utilization evaluation in a given region needs to be an on-going, continuous process. Lastly, high-risk pregnancy defined as pregnancy complicated by factors that can adversely affect outcome maternal or perinatal or both is an important determinant of drug use during pregnancy. ${ }^{7}$ It is estimated that about eight percent of pregnant women need drug treatment due to various chronic diseases and pregnancy related 
complications. $^{8}$ Recent studies suggest that high-risk pregnancy is quite prevalent and affects about one-third of pregnant women. ${ }^{9,10}$ Despite this, there is paucity of drug-utilization studies in high-risk pregnancy in Indian scenario.

The present study was thus undertaken to evaluate pattern of drug use and drug use according to WHO core-drug prescribing indicators as well as US-FDA pregnancy category in indoor patients of high-risk pregnancy.

\section{METHODS}

This prospective, observational study was conducted in the inpatient department of obstetrics and gynaecology of a tertiary care Government hospital during January 2014 to December 2014. Approval from institutional ethics committee was obtained and all the participants gave written informed consent to participate in the study.

All pregnant women with high-risk pregnancy diagnosed by a senior consulting gynaecologist admitted to obstetric ward in department of obstetrics and gynaecology, and willing to give voluntary informed consent were included in the study. High-risk pregnancy was defined as one where pregnancy is complicated by factors that may adversely affect outcome maternal or perinatal or both. High-risk pregnancy was said to be present when pregnant women presented with one or more of the following conditions:

\section{Pregnant women with medical disorders present before pregnancy $^{7}$}

Heart disease, pulmonary disease, hypertension, kidney disease, seizure disorder, sexually transmitted disease, diabetes mellitus, asthma, autoimmune disorders, thyroid disease, psychiatric illness.

\section{Pregnant women with complications of pregnancy}

Hyperemesis gravidarum, threatened abortion, hypertension in pregnancy, gestational diabetes, preterm labour, Rh incompatibility, polyhydraminos, oligohydramnios, third trimester bleeding, multiple gestations, infections in pregnancy, anaemia.

\section{Problems in previous pregnancy}

Recurrent abortions, previous still birth or neonatal death or birth of babies with congenital abnormalities, previous preterm delivery, grand multiparity (previous four or more viable births), previous caesarean section.

All indoor pregnant women without high-risk conditions (as outlined above) were excluded. Besides, following pregnant women with high-risk conditions were also excluded:
- Women not willing to give voluntary informed consent

- Women in whom language barrier prevented adequate communication

- Women admitted in labour

- Women discharged in short time before enrolment in the study.

Data regarding demographic characteristics, parity, associated medical, surgical, obstetric and gynaecological illness documented in indoor case paper was recorded on the predesigned case record form. The detailed information about drugs prescribed during the entire hospital stay such as number of drugs prescribed per prescription, number of antibiotics prescribed, number of injections prescribed, use of generic/brand names, drug dose, dosage form, frequency, duration of treatment was retrieved from medical and nursing charts. Considering possibility of drug intake by patients besides prescription drugs, patients were also interviewed to know about such drug intake. Some women delivered during hospital stay. The drugs used for induction of labour or for caesarean section and drugs given postpartum are not taken into account because as such these drugs are not specific for high-risk pregnancy condition.

Data was analysed by overall pattern of drug use was evaluated by calculating proportion of patients receiving a particular drug class. Drug utilization was also assessed according to five WHO core drug prescribing indicators as follows.

\section{Average number of drugs per encounter}

It was calculated by dividing the total number of different drug products prescribed by the number of encounters surveyed. All gravid women with high-risk pregnancy admitted to obstetric unit were included as "encounters" and followed for entire duration of their hospital stay. ${ }^{11}$ Fixed dose combination drugs were counted as single entity.

\section{Percentage of drugs prescribed by generic name}

It was a percentage, calculated by dividing the number of drugs prescribed by generic name by the total number of drugs prescribed, multiplied by 100 .

\section{Percentage of encounters with an antibiotic prescribed}

It was a percentage, calculated by dividing the number of patient encounters during which antibiotics were prescribed, by the total number of encounters surveyed, multiplied by 100 .

\section{Percentage of encounters with an injection prescribed}

It was a percentage, calculated by dividing the number of patient encounters during which injections were 
prescribed, by the total number of encounters surveyed, multiplied by 100 .

\section{Percentage of drugs prescribed from essential drug list}

It was a percentage, calculated by dividing the number of products prescribed which are listed on the national essential drugs list of India 2011 by the total number of products prescribed, multiplied by 100 .

Besides overall pattern and WHO core indicators, drug utilization was also assessed in relation to US-FDA pregnancy risk category, by classifying all prescribed drugs into US-FDA category A, B, C, D, X. ${ }^{12}$

\section{Statistical analysis}

Data was entered in Microsoft Excel 2008. Frequency and percentages of study parameters were calculated by using descriptive statistics.

\section{RESULTS}

Details of inpatients during study period are shown in Figure 1. The demographic data shown in Table 1 indicates that majority of women $(74.82 \%)$ were between 20-30 years of age and were admitted during third trimester of pregnancy.

Table 1: Demographic data of study population $(\mathbf{n}=\mathbf{2 9 0})$.

\begin{tabular}{|c|c|c|}
\hline Characteristic & Number of patients & Percentage \\
\hline \multicolumn{3}{|c|}{ Age Groups (years) } \\
\hline$<20$ & 65 & 22.41 \\
\hline $20-30$ & 217 & 74.82 \\
\hline$>30$ & 8 & 2.75 \\
\hline Total & 290 & 100 \\
\hline Mean age \pm SD & $23.31 \pm 3.338$ & \\
\hline \multicolumn{3}{|l|}{ Gravida } \\
\hline Primigravida & 138 & 47.58 \\
\hline Multigravida & 152 & 52.41 \\
\hline Total & 290 & 100 \\
\hline \multicolumn{3}{|l|}{ Trimester } \\
\hline First & 16 & 5.51 \\
\hline Second & 37 & 12.75 \\
\hline Third & 237 & 81.72 \\
\hline Total & 290 & 100 \\
\hline
\end{tabular}

Table 2: Overall pattern of drug use in study population $(n=290)$.

\begin{tabular}{|ll|}
\hline Drug Class Number of patients & Percentage* \\
\hline Vitamins and minerals $\quad 240$ & 82.75 \\
\hline Antihypertensive drugs 119 & 41.03 \\
\hline Antimicrobial agents $\quad 85$ & 29.31 \\
\hline Hormones and related drugs \\
\hline
\end{tabular}

\begin{tabular}{|lll|}
\hline $\begin{array}{l}\text { Antenatal } \\
\text { corticosteroids }\end{array}$ & 74 & 25.51 \\
\hline Progesterone & 25 & 8.62 \\
\hline Thyroxine & 19 & 6.55 \\
\hline Insulin & 4 & 1.33 \\
\hline Antithyroid drugs & 1 & 0.34 \\
\hline Oral antidiabetic & 1 & 0.34 \\
\hline Uterine relaxant & 55 & 18.96 \\
\hline $\begin{array}{l}\text { Antacids, Antireflux } \\
\text { Agents and Antiulcer } \\
\text { agents }\end{array}$ & 27 & 9.31 \\
\hline Antiemetic drugs & 14 & 4.82 \\
\hline Antipyretics & 10 & 3.44 \\
\hline Antiepileptic drugs & 8 & 2.75 \\
\hline Antihistaminic & 4 & 1.37 \\
\hline $\begin{array}{l}\text { Drugs acting on } \\
\text { respiratory system }\end{array}$ & 2 & 0.68 \\
\hline Analgesics & 1 & 0.34 \\
\hline Others & 32 & 11.03 \\
\hline
\end{tabular}

* The sum total of percentage exceeds 100 as some patients received more than one drug class.

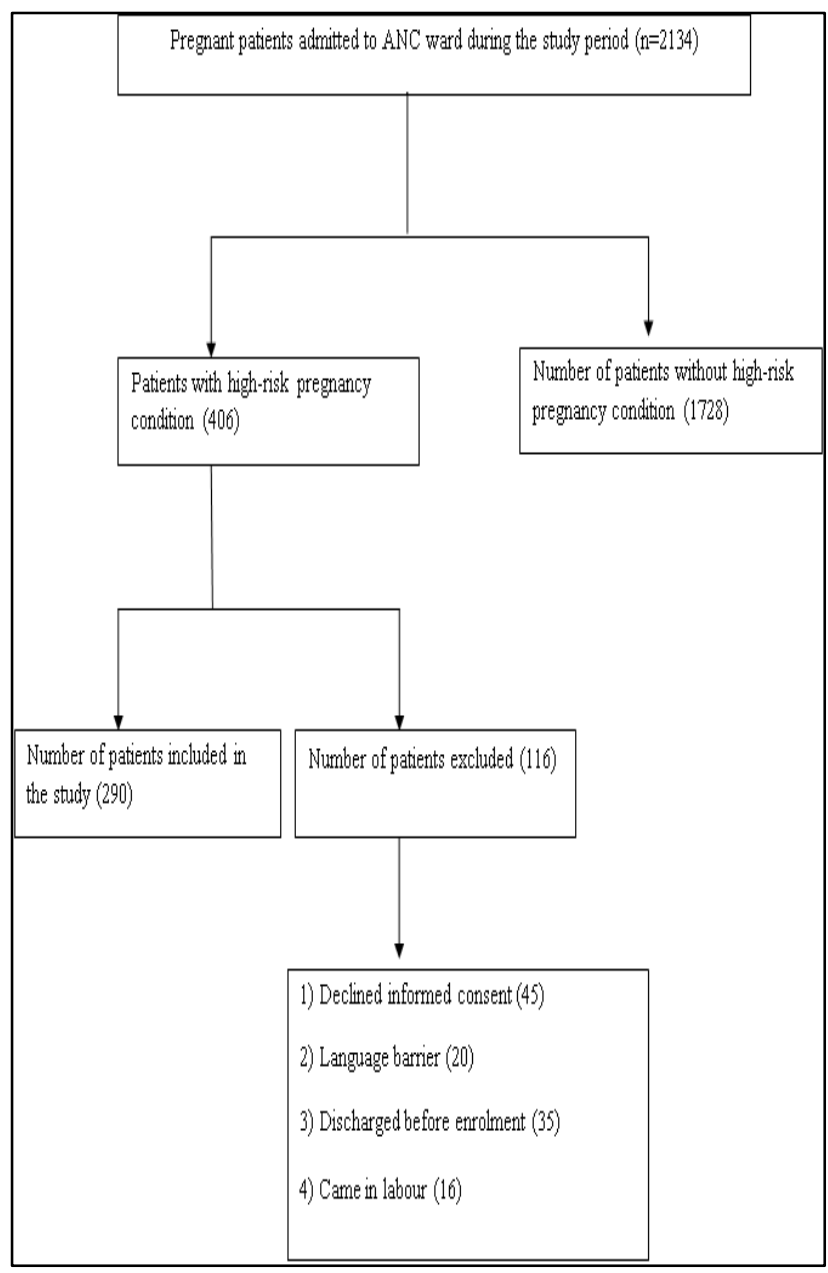

Figure 1: Patient flow diagram. 
Table 2 shows overall pattern of drug use in study population. The most commonly prescribed drug class was vitamins and minerals prescribed in 240/290 $(82.75 \%)$ patients which included iron, folic acid, vitamin C, calcium and multivitamin B complex. Hormones and related agents were prescribed in 124/290 (42.75\%) of patients, which comprised antenatal corticosteroids in $74 / 290(25.51 \%)$ and progesterone in $25 / 290(8.62 \%)$ patients. Other commonly prescribed drug classes were antihypertensive $(119 / 290,41.03 \%)$, antimicrobials $(85 / 290,29.31 \%)$ and uterine relaxant isoxsuprine $(55 / 290,18.96 \%)$.

\section{Table 3: WHO core drug prescribing indicators.}

\begin{tabular}{|ll|}
\hline Prescribing Indicator & Value \\
\hline $\begin{array}{l}\text { Average number of drugs per } \\
\text { encounter }\end{array}$ & 6.4 \\
\hline $\begin{array}{l}\text { Percentage of drugs prescribed by } \\
\text { generic name }\end{array}$ & $73.07 \%$ \\
\hline $\begin{array}{l}\text { Percentage of encounters with an } \\
\text { antibiotic prescribed }\end{array}$ & $29.31 \%$ \\
\hline $\begin{array}{l}\text { Percentage of encounters with an } \\
\text { injection prescribed }\end{array}$ & $65.17 \%$ \\
\hline $\begin{array}{l}\text { Percentage of drugs prescribed from } \\
\text { essential drug list }\end{array}$ & $77.07 \%$ \\
\hline
\end{tabular}

The values of WHO core drug prescribing indicators are depicted in Table 3. Average number of drugs per encounter was 6.4. Percentage of drugs prescribed by generic name and from essential drug list was $73.07 \%$ and $77.07 \%$ respectively. Percentage of encounters with an antibiotic and an injection prescribed was $29.31 \%$ and $65.17 \%$ respectively.

Table 4: US-FDA pregnancy drug category classification $(n=290)$.

\begin{tabular}{|lll|}
\hline US-FDA category & Number of patients & Percentage* \\
\hline A & 267 & 92.06 \\
\hline B & 251 & 86.55 \\
\hline C & 214 & 73.79 \\
\hline D & 14 & 4.82 \\
\hline X & 0 & 0 \\
\hline
\end{tabular}

* The sum total of percentage exceeds 100 as some patients received more than one drug class.

Table 4 shows classification of drugs according to USFDA pregnancy-drug categories. In the present study 267/290 (92.06\%) patients were prescribed drugs belonging to category A, 251/290 (86.55\%) patients were prescribed category B drugs, 214/290 (73.79\%) patients were prescribed category C drugs and 14/290 (4.82\%) patients were prescribed drugs belonging to category D. Medications used in 33/290 (17.37\%) patients did not have a category as per the US-FDA classification system. These included arginine, essential amino acids, lactobacilli, disodium citrate.

\section{DISCUSSION}

The crucial input for planning effective strategies to improve drug use is provided through drug utilization studies. WHO core drug use indicators are especially useful in drug utilization research as these indicators measure performance of health care providers in several key dimensions related to the appropriate use of drugs. ${ }^{13}$ Given the possibility of harmful effects of drugs on unborn fetus, consideration of US-FDA pregnancy drug category is also an important aspect of drug utilization studies in pregnant women.

This prospective, observational, hospital based study involved 290 pregnant women with high-risk condition during the study period of one year. The demographic data indicated that majority of women were under 30 years of age and high-risk pregnancy was seen with somewhat higher frequency in multigravida than in primigravida $(52.41 \%$ versus $47.58 \%)$. Similar results have been reported by previous studies. ${ }^{14}$

Most of the women attending this hospital come from lower socioeconomic class. High prevalence of poor nutritional status, vitamin and mineral deficiencies in this class warrants prophylactic use of vitamins and minerals. ${ }^{15}$ Routine supplementation of iron, folic acid and calcium is recommended in pregnant women in developing countries. ${ }^{16}$ Accordingly most commonly used medications (in $82.45 \%$ of women) in the present study were iron, folic acid, calcium and multivitamin B complex (Table 2). Our results are in accordance with previous Indian studies though some other studies report lower use of iron and folic acid during pregnancy. $8,14,17,18$ The use of other drugs such as antihypertensive drugs, gastrointestinal drugs, uterine relaxants, antiepileptic drugs, hormones were largely problem oriented (Table 2) and is in accordance with earlier studies. ${ }^{14}$

\section{Drug utilization in terms of WHO core drug use indicators}

The WHO core drug use indicators are quick and efficient means of assessing potential problems in drug use in many health care settings. Assessment of these indicators is depicted in Table 3. Average number of drugs per encounter was 6.4 in present study. This value is closer to value of 6.58 reported in hospitalized patients of high-risk pregnancy. ${ }^{14}$ While average number of drugs per prescription in outdoor pregnant patients is reported to be about three. ${ }^{19,20}$ The use of higher number of drugs in indoor patients of high-risk pregnancy can be explained by use of drugs for high-risk conditions in addition to routine use of vitamins and minerals.

The values of percentage of drugs prescribed by generic name $(73.07 \%)$ and percentage of drugs prescribed from essential drug list $(77.07 \%)$ in the present study are closer to values $(62.8 \%$ and $80.79 \%)$ reported by study of Patel et al. ${ }^{14}$ As higher percentages of drugs were prescribed 
from essential drugs list, it suggests rationality of drug use pattern and degree to which practices conform to a national drug policy. Prescribing by generic names offers several advantages such as low cost of drug therapy, clear identification of a drug, easy information exchange, increased patient adherence and equivalent therapeutic benefits as brand name alternatives. ${ }^{21}$ Despite these advantages, in $26 \%$ of cases prescribing was done by brand names in the present study. This finding and the fact that drugs are purchased by generic names in the government hospitals points towards need for intervention to improve prescribing practices of physicians.

Percentage of encounters with an antibiotic prescribed was $29.31 \%$ which is closer to the value reported by Patel KP. ${ }^{14}$ Percentage of encounters with an injection prescribed is understandably high in indoor patients of high-risk pregnancy. But the value of this indicator in the present study is more than double compared to value reported in a study by Patel et al $(25.29 \%$ versus $65.17 \%) .{ }^{14}$ This higher value is mainly attributed to parenteral antenatal corticosteroids, uterine relaxants, iron, antibiotics and magnesium sulphate and indicates variable morbidity pattern and therapeutic practices.

\section{US-FDA pregnancy-drug categories}

US-FDA pregnancy-drug categories based on evidence obtained from animal and/or human studies help physicians to choose safer drugs during pregnancy. In the present study majority of drugs belonged to category A, B and $\mathrm{C}$ and none of pregnant women received drugs from category $\mathrm{X}$. This finding indicates satisfactory awareness regarding drug induced risk to fetus among physicians. Only $14 / 290$ patients $(4.82 \%)$ in the present study received drugs from category $D$ which entails positive risk to fetus. These category D drugs were antiepileptic drugs, antiretroviral drugs (efavirenz) and antithyroid drugs (propylthiouracil). Their use was justified in the present study since benefit outweighed the risks. Our finding largely conforms to previous studies. ${ }^{14}$ For some of the medicinal products used in study population USFDA pregnancy category was not available. Some of these products like arginine, essential amino acids, lactobacilli, disodium citrate though are not known to be harmful, specific safety data would be useful.

There are several limitations to the present study. It is noteworthy that choice of drugs in government hospitals is generally restricted to the drugs available in the hospital. Such restrictions are somewhat relaxed for pregnant women as pregnant women are entitled to receive free treatment under Janani Shish Suraksha Karyakarm (JSSK) run by government of India. ${ }^{22}$ Still, the drug utilization pattern in government hospital which primarily caters to the needs of people from lower socioeconomic strata cannot be generalised to other health care sectors offering different levels of healthcare or catering to patients from higher socioeconomic strata. About $28 \%$ of patients with high-risk pregnancy were excluded from the present study for reasons described earlier. Still more than $70 \%$ of patients with high-risk pregnancy were included which is fair enough to give idea about drug utilization. The inherent limitation of WHO drug use prescribing indicators is that these are general indicators and by themselves do not refer to particular problem or lead to focused intervention to improve drug use. Thus except for failure to use generic names in $26 \%$ of cases, the present study cannot tell whether use of antibiotics in $29.31 \%$ cases or use of injections in $65.17 \%$ cases was appropriate or not. Further studies would be needed to see appropriateness of prescribed drugs in relation to illness.

\section{CONCLUSION}

In conclusion, vitamins, minerals, antihypertensive and antenatal steroids were most commonly used drugs in indoor patients of high-risk pregnancy. Most of the drugs prescribed belonged to National Essential Drug List, generic name was used for most of the drugs and nearly two-thirds of patients received injections. Majority of the drugs belonged to US-FDA pregnancy drug category A, B and C. Further studies to know appropriateness of drug use and to understand knowledge, attitude and practices of prescribers and patients will be helpful to plan targeted interventions to improve drug use.

\section{ACKNOWLEDGEMENTS}

We are thankful to Department Obstetrics and Gynecology, Government Medical College and Hospital, Miraj for their co-operation during the study.

\section{Funding: No funding sources}

Conflict of interest: None declared

Ethical approval: The study was approved by the Institutional Ethics Committee

\section{REFERENCES}

1. WHO International working group for drug statistics methodology. Introduction to drug utilization research. Oslo, Norway: WHO collaborating centre for drug utilization research and clinical pharmacology 2003. Available at http://apps.who.int/medicinedocs/pdf/s4876e/s4876e. pdf. Accessed 12 July 2015.

2. Daw JR, Hanley GE, Greyson DL, Morgan SG. Prescription drug use during pregnancy in developed countries: a systematic review. Pharmacoepidemiol Drug Saf. 2011;20(9):895-902.

3. De Jonge L, Bos HJ, van Langen IM, de Jong-van den Berg LT, Bakker MK. Antibiotics prescribed before, during and after pregnancy in the Netherlands: a drug utilization study. Pharmacoepidemiol Drug Saf. 2014;23(1):60-8.

4. Profit J, Goldstein BA, Tamaresis J, Kan P, Lee HC. Regional variation in antenatal corticosteroid use: a 
network-level quality improvement study. Pediatrics. 2015;135(2):e397-404.

5. Eurap study group. Utilization of antiepileptic drugs during pregnancy: comparative patterns in 38 countries based on data from the EURAP registry. Epilepsia. 2009;50(10):2305-9.

6. Bobo WV, Davis RL, Toh S, Li DK, Andrade SE, Cheetham TC, et al. Trends in the use of antiepileptic drugs (AEDs) among pregnant women in the U.S., 2001-2007: a medication exposure in pregnancy risk evaluation program (MEPREP) study. Paediatric and perinatal epidemiology. 2012;26(6):578-88.

7. Datta DC. Special topics in obstetrics. In: Konar H, ed. DC Dutta's Textbook of obstetrics. $8^{\text {th }}$ ed. New Delhi: Jaypee Brothers Medical Publishers; 2015:692-723.

8. Sharma R, Kapoor B, Verma U. Drug utilization pattern during pregnancy in North India. Indian J Med Sci. 2006;60(7):277-87.

9. Kumar MP, Gnanadeep NV, Dixit UR, Patil PS. Prevalence of high risk pregnancy in rural Dharwad. IOSR Journal of Dental and Medical Sciences. 2015;14(10):29-32.

10. Bharti, Kumar V, Kaur A, Chawla S, Malik M. Prevalence and correlates of high risk pregnancy in rural Haryana: a community based study. International Journal of Basic and Applied Medical Sciences. 2013;3(2):212-7.

11. Kumar S, Bansal D, Hota D, Jain M, Singh P, Pandey BL. Assessment of clinical outcomes and prescribing behavior among in patients with severe preeclampsia and eclampsia: an Indian experience. Indian $\mathrm{J}$ Pharmacol. 2014;46(1):18-23.

12. Schimmer BP, Parker KL. Contraception and pharmacotherapy of obstetrical and gynecological disorders. In: Brunton LL, Chabner BA, Knollman BC, eds. Goodman and Gilman's the pharmacological basis of therapeutics. $12^{\text {th }}$ ed. New York: McGrawHill; 2011:1833-1852.

13. WHO. How to investigate drug use in health facilities: selected drug use indicators. (WHO/DAP/93.1). Geneva: Action Programme on Essential Drugs, World Health Organization. 1993;187. Available at apps.who.int/medicinedocs/en/d/Js2289e/. Accessed 15 February 2015.
14. Patel KP, Joshi HM, Patel VJ. A study of morbidity and drug utilization pattern in indoor patients of high risk pregnancy at tertiary care hospital. Int J Reprod Contracept Obstet Gynecol. 2013;2(3):372-8.

15. Good clinical practice recommendations for iron deficiency anemia in pregnancy (IDA) in pregnancy in India. Journal of Obstetrics and Gynaecology of India. 2011;61(5):569-71.

16. WHO/UNICEF/UNU. Iron deficiency anaemia assessment, prevention, and control: a guide for programme managers. Geneva: World Health Organization; 2001. Available at http://www.who.int/nutrition/publications/en/ida_ass essment_prevention_control.pdf. Accessed 10 May 2015.

17. Gawde SR, Bhide SS, Patel TC, Chauhan AR, Mayadeo NM, Sawardekar SB. Drug prescription pattern in pregnant women attending antenatal outpatient department of a tertiary care hospital. British Journal of Pharmaceutical Research. 2013;3(1):1-12.

18. Reddy SB, Patil N, Hinchageri SS, Kamala S. Assessing the pattern of drug use among pregnant women and evaluating the impact of counseling on medication adherence among them. International Research Journal of Pharmacy. 2011;2(8):148-53.

19. Adhikari A, Biswas S, Gupta RK. Drug utilization pattern in pregnant women in rural areas, India: cross-sectional observational study. J Obstet Gynaecol Res. 2011;37(12):1813-7.

20. Joshi H, Patel S, Patel K, Patel V. Drug use pattern during pregnancy: a prospective study at tertiary care teaching hospital. NHL Journal of Medical Science. 2012;1(1):14-7.

21. Haas JS, Phillips KA, Gerstenberger EP, Seger AC. Potential savings from substituting generic drugs for brand-name drugs: medical expenditure panel survey, 1997-2000. Ann Intern Med. 2005;142(11):891-7.

22. MOHFW. Guidelines for Janani-Shishu Suraksha Karyakram (JSSK). New Delhi: Maternal Health Division, Ministry of Health and Family Welfare, Govt. of India 2011. Available at http://nrhm.gov.in/images/pdf/programmes/jssk/guid elines/guidelines_for_jssk.pdf. Accessed 10 July 2015.

Cite this article as: Gaidhankar SL, Pore SM, Deokate MN, Ramanand SJ, Salunke AT. A study of drug utilization in indoor patients of high-risk pregnancy in a tertiary care hospital. Int J Basic Clin Pharmacol 2016;5:1366-71. 